\title{
Eco-friendly chopped tire rubber as reinforcements in fly ash based geopolymer concrete
}

\author{
Isam Mohamad Ali ${ }^{1}$, Ahmed Samir Naje ${ }^{2},{ }^{*}$ and Mohammed Salah $\mathrm{Nasr}^{3}$ \\ ${ }^{1}$ Karbala Technical Institute, Al-Furat Al-Awsat Technical University, 56001 Karbala, Iraq \\ ${ }^{2}$ College of Water Resources Engineering, Al-Qasim Green University, Babylon, Iraq \\ ${ }^{3}$ Babylon Technical Institute, Al-Furat Al-Awsat Technical University, 51015 Babylon, Iraq \\ Received: 27/07/2019, Accepted: 23/08/2020, Available online: 04/09/2020 \\ *to whom all correspondence should be addressed: e-mail: ahmednamesamir@yahoo.com \\ https://doi.org/10.30955/gnj.003192
}

\section{Graphical abstract}

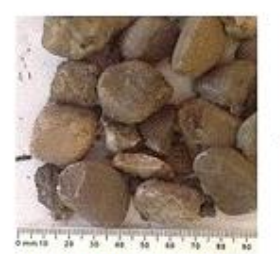

Concrete aggreg ate

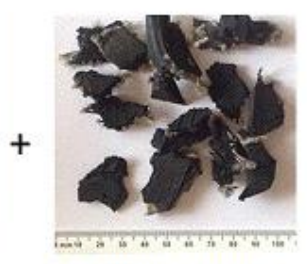

Tire rubber Particles

$\downarrow$

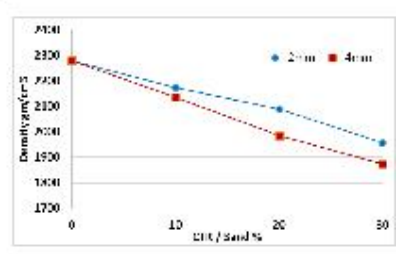

The 28d compressive strength and density at various CTR to sand ratios.

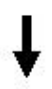

Concrete product Eco-efficient

Low energy

High recycled volume Impact resistant

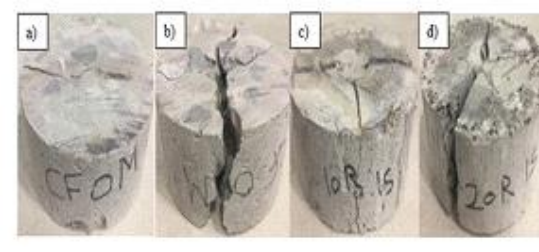

\section{Abstract}

One of the major challenges faced by researchers is to recycle industrial wastes in a manner that reduces their environmental impact in nature. An experimental study was carried out to determine the suitability of using chopped tire rubber as reinforcements in green and sustainable geopolymer concrete, with the purpose of using them as nonstructural products. The geopolymer mixture was made by mixing of fly ash powder, fine aggregate, and Superplasticizer in $\mathrm{Na}_{2} \mathrm{SiO}_{3} / \mathrm{NaOH}$ solution. Mixtures were divided into four different groups, with constant water to fly ash ratio of 0.12 and alkaline dosage of $45 \%$ by weight of fly ash, based on the recycled chopped tire rubber (CTR) content: $0,10,20$, and $30 \%$ by volume of fine aggregate with two maximum sizes (2 and $4 \mathrm{~mm}$ ). Hardened properties of resulted geopolymer like compressive strength, density; and ultrasonic pulse velocity were examined at $28 \mathrm{~d}$. Besides that, X-Ray diffractometer and Scanning Electron Microscope were used in order to observe the microstructure of the resulted geopolymer concrete. In view of the consequences for this study, it is preferable to replace no more than $10 \%$ of fine aggregate in geopolymer concrete by CTR. In addition, according to SEM photographs, increasing the CTR content more voids will be pronounced and thus, decreasing the mechanical performance.

Keywords: Fly ash, geopolymer, strength, microstructure, UPV, chopped tire rubber CTR, XRD, SEM.

\section{Introduction}

It is well known that using waste materials in the manufacturing of building units such as geopolymer concrete, is an opportunity to reduce their environmental impact. "Geopolymer is an alumino-silicate reactive materials with strongly alkaline solutions" (Nurruddin et al., 2018). Geopolymer, has properties such as low consumption of raw resources, no $\mathrm{CO}_{2}$ emission, less energy consumption, low production costs, and low heat of hydration. These properties make geopolymer discover incredible applications in numerous fields of industry like civil engineering (Al-Shathr et al., 2019).

Davidovits stated that geopolymerization might be too close to zeolite formation, although the geopolymer microstructure is amorphous to semi-crystalline rather than crystalline. He also stated that geopolymers have a three-dimensional structure and belong to the group of zeolites and feldspathoids. The designation of geopolymers based on aluminosilicate is called poly (sialates) involving an amorphous network of $\mathrm{AlO}_{4}$ and $\mathrm{SiO}_{4}$ tetrahedara linked interchangeably by sharing all the oxygens in the form of silicon-oxo-aluminate (-Si-O-Al-O-) and abbreviated as sialate. The presence of positive ions, such as $\mathrm{Na}^{+}, \mathrm{K}^{+}$, and 
$\mathrm{Ca}^{++}$, in the framework is necessary to balance the negative charge of $\mathrm{Al}^{3+}$ in IV-fold coordination with oxygen. This polymeric response is similar to the formation of zeolites and zeolite precursors. The same findings for fly ash geopolymer concrete production were also documented by Komljenovi (Komljenović et al., 2010) even when sodium hydroxide is prepared with sodium silicate (water glass) for making ready solution and then added to powder fly ash.

Bernal et al. (2011) studied the addition of slag to Metakaolin based geopolymer concrete. Slag caused as 0 , 20, 40, 60 and 80 percent replacement of metakaolin modified the compressive strength increased as compared with geopolymer concrete synthesis by metakaolin only, the optimum percentage was 60 percent.

In a related study, the detrimental effect created by the addition of waste fibers is due to the initiation of more pores and microcracks into the matrix. An increase in pores may be because of the poor workability of a larger fiber volume fractions, which made compaction difficult (Shanthini et al., 2016). The increased number of microcracks with high fiber volume fractions is due to fibers touching one-another, resulting in fibers that are poorly bonded or even unbounded in the matrix and this creates weak zones (Kumaravel and Sivakumar, 2018).

Parveen et al. (2018) investigated the influence of incorporating alccofine on the properties of fly ash based geopolymer concrete at ambient temperature. The results showed that specimens prepared with alccofine have an important impact on the polymerization of the geopolymer concrete, that lead to improve the strength and microstructural characteristics.

This study is an attempt mainly to understand the microstructural and mechanical performance of sustainable fly ash geopolymer concrete with and without chopped tire rubber as a replacement of fine aggregate. The second important objective is to find a direct relationship between the investigated mechanical properties and UPV. So, it become too easy to estimate strength in terms of direct pulse transmission. In addition to reduce the harmful environmental impacts of some industrial wastes.

\section{Materials}

The raw materials used to produce geopolymer are fly ash powder, natural sand, coarse aggregate, super plasticizer, tap and distilled water and alkaline activator (Sodium Silicate + Sodium Hydroxide). The chemical composition of the fly ash is presented in Table 1, which indicated that they are compatible with the requirements of ASTM C-311 (ASTM C311/C311M) and ASTM C-618 (ASTM C-618) Class F specifications with strength activity index of $118 \%$ at $7 d$. The alkaline solution was prepared using Sodium silicate $\left(\mathrm{Na}_{2} \mathrm{SiO}_{3}\right)$, fabricated in the United Arab Emirates. The concentration of the $\mathrm{Na}_{2} \mathrm{SiO}_{3}$ depends on the ratio of $\mathrm{Na}_{2} \mathrm{O}$ to $\mathrm{SiO}_{2}$ anticipated. Commercial sodium hydroxide $(\mathrm{NaOH})$, with $99 \%$ purity in flake form was utilized. The solids should be dissolved in distilled water to form an activator with the desired molar concentration (10 M). A total of $12 \%$ (by weight of FA) was added to increase the homogeneity of the producing geopolymer. Quartz-based natural sand that conforms to I.Q.S No.45 (Iraqi Standard No. 45), zone 3 was employed as a fine aggregate.

Table 1. Chemical composition of fly ash*

\begin{tabular}{ccc}
\hline Constituent & Fly Ash (\%) & $\begin{array}{c}\text { Limits of ASTM C- } \\
618 / 05\end{array}$ \\
\hline $\mathrm{CaO}$ & 1.20 & $\geq 70 \%$ \\
\hline $\mathrm{SiO}_{2}$ & 49.6 & \\
\hline $\mathrm{Al}_{2} \mathrm{O}_{3}$ & 44.9 & $\leq 5$ \\
\hline $\mathrm{Fe}_{2} \mathrm{O}_{3}$ & 4.00 & \\
\hline $\mathrm{SO}_{3}$ & 0.18 & $\leq 6 \%$ \\
\hline $\mathrm{NaOH+KOH}$ & --- & $\leq 34 \%$ \\
\hline Loss on Ignition & 2.4 & \\
\hline Fineness & $20 \%$ &
\end{tabular}

*Chemical tests were made by the National Center for Geological Survey and Mines, Baghdad, Iraq

Tables 2 and 3 show the grading of chopped rubber and fine aggregates used in this paper, and the chemical composition of CTR respectively. Rheobuild SP1 (commercially known as Master RHEOBULD SP1) highrange water reducer superplasticizer was utilized in all mixtures. Rheobuild SP1 is designed specially to impart rheoplastic qualities to concrete. It is a modified Sulphonated naphthalene based chemical aqueous solution, purchased from Sika Company in Iraq. The properties of Rheobuild SP1 are followed the ASTM C 494 (ASTM C494/C494M and ASTM 494/C 494M) Type F. Crushed gravel of $10 \mathrm{~mm}$ maximum size obtained from AlNebai quarry (middle of Iraq) was used as the coarse aggregate in all mixes. The results show that coarse aggregate conforms to the Iraqi Standard IQS 45 (Iraqi Standard No. 45).

Table 2. Grading of fine aggregate and chopped tire rubber*

\begin{tabular}{cccccccc}
\hline \multicolumn{7}{c}{ Sieve size $(\mathrm{mm})$} \\
\hline Item & 10 & $\mathbf{4 . 7 5}$ & $\mathbf{2 . 3 6}$ & $\mathbf{1 . 1 8}$ & $\mathbf{0 . 6 0}$ & $\mathbf{0 . 3 0}$ & $\mathbf{0 . 1 5}$ \\
\hline $\begin{array}{c}\text { Fine } \\
\text { aggregate }\end{array}$ & 100 & 95 & 78 & 56 & 43 & 15 & 6 \\
\hline $\begin{array}{c}\text { Chopped } \\
\text { Rubber } \\
\text { Tires }\end{array}$ & 100 & 100 & 97 & 83 & 28 & 7 & 0 \\
\hline
\end{tabular}

*Tests were made by the Concrete Laboratory in Karbala Technical Institute, Karbala, Iraq

Table 3. Chemical composition of chopped tire rubber*.

\begin{tabular}{cc}
\hline $\begin{array}{c}\text { Rubber hydrocarbon } \\
\text { (SBR) }\end{array}$ & $47.7 \%$ \\
\hline Carbon black & $30.7 \%$ \\
\hline Acetone extract & $15.6 \%$ \\
\hline Ash & $2.1 \%$ \\
\hline Residue chemical balance & $3.9 \%$ \\
\hline Density & $620 \mathrm{~kg} / \mathrm{m}^{3}$ \\
\hline
\end{tabular}

* Results according to the manufacturer

\section{Experimental procedure}

Since there is no committee that specify the mix proportions of geopolymer concrete, so the mix used in this work shown in Table 4 as previously proposed by Ali et al. 
(2019). Three concrete samples were chosen for each test carried out for $28 \mathrm{~d}$ to investigate compressive strength, density and UPV. The compressive strength and density tests were done using $100 \mathrm{~mm}$ cubes according to BS 1881: Part 116 (BS 1881: Part 116) and BS 1881: Part 114 (BS 1881: Part 114) standards respectively. Meanwhile, ultrasonic pulse velocity test was done using $100 \mathrm{~mm}$ cubes specimens according to BS 1881: Part 203 (BS 1881: Part 203) standard. After casting the specimens, hot curing technique was used in water of $60^{\circ} \mathrm{C}$ for $48 \mathrm{hrs}$ followed by moist curing until the testing day.
In addition, in order to characterize their reaction products, geopolymer concrete samples from each of the four mixtures were analyzed using X-ray diffractometer (XRD) analysis. The textural study of the fractured surface for the samples was performed using (SEM Model: TESCANVEGA/USA) with tungsten source and detector X-Flasb 5030 , which operates at a voltage of $1-20 \mathrm{kV}$ with a range of between 10 and 80,000 - magnification, at a work distance from 1 to $10 \mathrm{~mm}$.

Table 4. Mix proportions

\begin{tabular}{|c|c|c|c|c|c|c|c|}
\hline \multirow[b]{2}{*}{ Mix No. } & \multirow{2}{*}{$\begin{array}{l}\text { Fly ash } \\
\left(\mathrm{kg} / \mathrm{m}^{3}\right)\end{array}$} & \multicolumn{2}{|c|}{ Fine aggregate } & \multirow[b]{2}{*}{$\mathrm{SP}\left(\mathrm{kg} / \mathrm{m}^{3}\right)$} & \multirow{2}{*}{$\begin{array}{c}\text { Coarse } \\
\text { aggregate } \\
\left(\mathrm{kg} / \mathrm{m}^{3}\right)\end{array}$} & \multirow{2}{*}{$\begin{array}{c}\mathrm{Na}_{2} \mathrm{SiO}_{3} / \\
\mathrm{NaOH} \text { by w.t } \\
\text { of } \mathrm{FA} \mathrm{( \% )}\end{array}$} & \multirow{2}{*}{$\begin{array}{l}\text { CTR by vol. } \\
\text { of sand }\end{array}$} \\
\hline & & $\mathrm{kg} / \mathrm{m}^{3}$ & $\mathrm{~m}^{3}$ & & & & \\
\hline Control & \multirow{4}{*}{400} & 720 & 0.465 & \multirow{4}{*}{8} & \multirow{4}{*}{1100} & \multirow{4}{*}{45} & 0 \\
\hline M10 & & 647 & 0.418 & & & & 10 \\
\hline M20 & & 576 & 0.372 & & & & 20 \\
\hline M30 & & 505 & 0.326 & & & & 30 \\
\hline
\end{tabular}

\section{Results and discussion}

The replacement of chopped tire rubber as a percentage volume of fine aggregate, to geopolymer concrete mixtures after $28 \mathrm{~d}$ have been investigated and discussed. However, the increase in the compressive strength shown in Figure 1, of specimens containing $10 \%$ chopped tire rubber was more than that of control due to the low voids as the scanning electron microscope prove later. Chopped tire rubber which is beneficial for bridging of micropores and hence, enhancement of the final strength by $9.6 \%$ and 2.0 $\%$ for $2 \mathrm{~mm}$ and $4 \mathrm{~mm}$ respectively. On contrasts, it is obvious from results that as the percentage of chopped tire rubber increases more than $10 \%$, the compressive strength decreases for mixes $\mathrm{M} 20$ and $\mathrm{M} 30$ as compared to that of control. The reduction in compressive strengths at $20 \%$ and $30 \%$ of CTR replacement were of (18.6 and 26.9) \% and (21.2 and 37.1) \% for 2 and $4 \mathrm{~mm}$ respectively. This could be attributed to the low specific gravity of CTR and/or to the increase in the number and size of micropores. The same results were reported by Maranan et al. (2015).

Figure 2 shows the relationship between the oven dry densities for all geopolymer concrete mixes containing chopped tire rubber as compared to control mix. The results illustrate that geopolymer mixes containing CTR have lower oven dry density relative to that of control. Furthermore, increasing the $2 \mathrm{~mm}$ chopped tire rubber to fine aggregate ratios by 10,20 and $30 \%$ decreases the oven dry density of $4.6,8.3$ and $14.1 \%$ respectively. While, the reductions became of $6.3,12.9$ and $17.8 \%$ as the chopped tire rubber maximum size was increased to $4 \mathrm{~mm}$. This is due to the low specific gravity of the used chopped tire rubber and more initiated pores in internal structure. However, the densities of geopolymer concrete are close to density of normal concrete, which varies in the range of $2200-2500 \mathrm{~kg} / \mathrm{m}^{3}$. This is in agreement with the pervious findings by Al-Shathr et al. (2016).

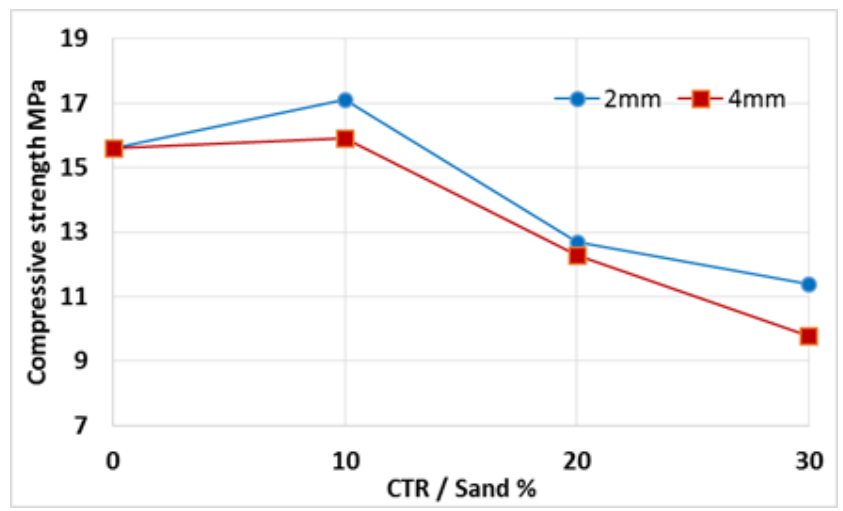

Figure 1 . The $28 \mathrm{~d}$ compressive strength at various CTR to sand ratios

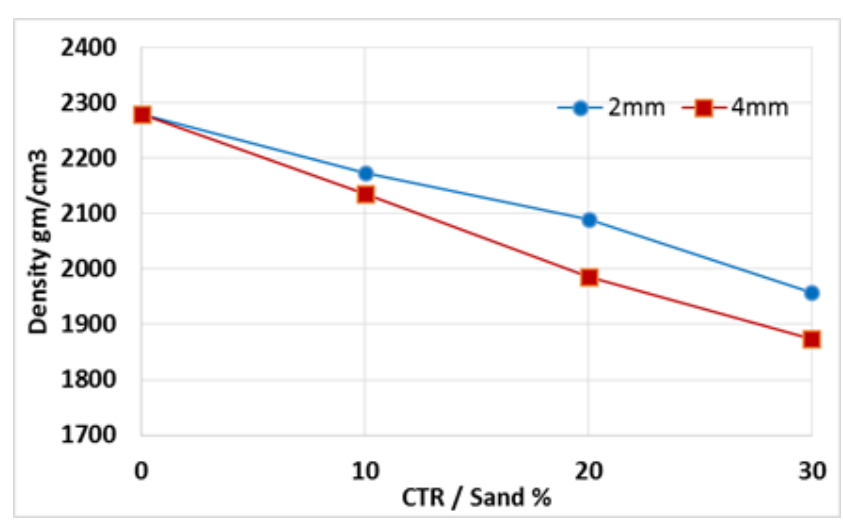

Figure 2. The $28 \mathrm{~d}$ density at various CTR to sand ratios

The UPV test is used to estimate the uniformity and quality of geopolymer concrete, and the present of voids. Figure 3 presents the relationship between ultrasonic pulse velocity and chopped tire rubber of different maximum size ( 2 and $4 \mathrm{~mm}$ ). From this figure, there is almost a linear decrease in the pulse transmission of studied specimens with the increase in the chopped tire rubber to sand ratios. Like density, the replacement of $2 \mathrm{~mm} \mathrm{CTR}$ to geopolymer 
concrete mixtures by 10,20 and $30 \%$ by volume of sand resulted in a decline of the UPV for all specimens after $28 \mathrm{~d}$ by $9.6,14.0$ and $20.5 \%$ respectively. However, the reductions became of $15.8,18.3$ and $31.4 \%$ as the chopped tire rubber maximum size was increased to $4 \mathrm{~mm}$. Similar findings were obtained by Kim and Kim (Kim and Kim).

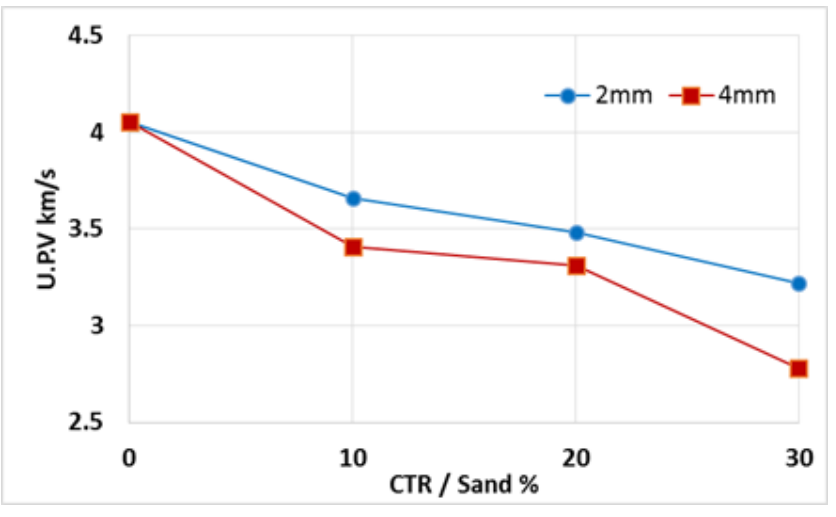

Figure 3. The 28d U.P.V at various CTR to sand ratios

The following equations shown in Figure 4 may be suggested to fit the relationship between compressive strength and Ultrasonic Pulse Velocity for fly ash geopolymer concrete associated with good accuracy. Equation 1 is used for geopolymer concrete with $2 \mathrm{~mm}$ CTR maximum size, meanwhile, equation 2 is used for geopolymer concrete with $4 \mathrm{~mm}$ CTR.

$$
\begin{aligned}
& f c=3.45 e^{0.3941 v} \\
& f c=4.05 e^{0.3486 v}
\end{aligned}
$$

where:

$f c=$ Compressive strength in MPa, $v=$ direct pulse velocity in $\mathrm{km} / \mathrm{s}$.

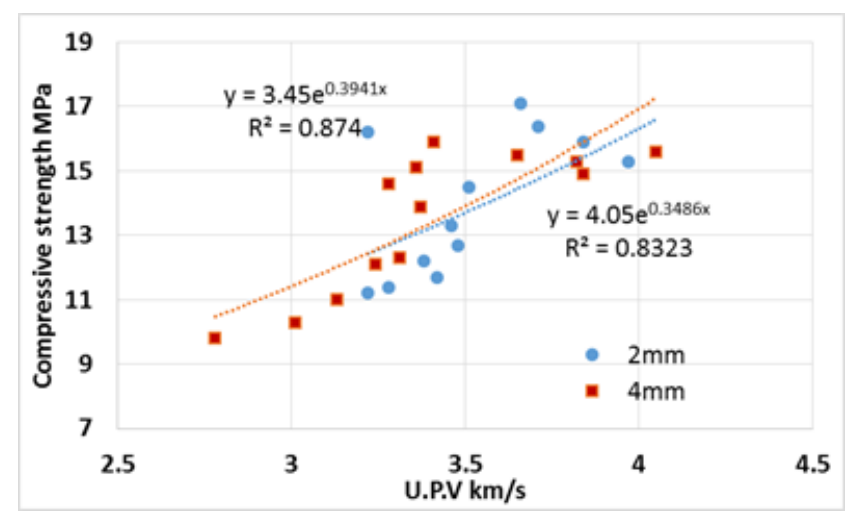

Figure 4. Predicted equations for compressive strength of geopolymer concrete with UPV at $28 \mathrm{~d}$

The lower fitting curve $(2 \mathrm{~mm})$ shows better-fit nonlinear regression curve. This curve minimizes the sum-of-squares of the vertical distances of the points indicating good relevance between experimental data and the theoretical data. In this curve, the sum of squares of those distances equals 0.8323 . The upper fitting curve $(4 \mathrm{~mm})$ of the figure shows the $R^{2}$ of 0.874 . According to Mulholland and Hibbert (1997), $R^{2}$ with a value $>80 \%$ is usually considered a strong relationship between any two variables. Additionally, Kurtoğlu et al. (2018) described the expression which had $\mathrm{R}^{2}$ of 0.84 in their work as a good relationship. Therefore, these formulas may be appropriate for geopolymer concrete.

$\mathrm{X}$-ray powder diffraction is a powerful technique to study semi-crystalline materials like geopolymer. According to Figure 5, semi crystalline peaks were noticed in all of the investigated mixes. Moreover, for all the specimens, welldefined diffraction peaks of Quartz (Q) were observed at $2 \theta=12.2^{\circ}, 28.1^{\circ}$ and $32.3^{\circ}$. All the other lower peaks correspond to the Aluminum Mullites, Merwinites, and Calcium silicates are also noticed. The highest peaks intensities were observed at $2 \theta=28.1^{\circ}$ for control mix due to the presence of Quartz. After the addition of CTR, highest peaks intensities were observed at $2 \theta=32.3^{\circ}$ for M10, M20 and M30 respectively. Amorphous peaks intensities of geopolymerization were also observed and was not easy to indicate. The percentages of amorphous silicates were more in the case of $\mathrm{M} 30$ mix. It shows that at higher percentage of CTR in the geopolymer concrete indicates less crystallinity. The same trend was found by Parveen et al. (2018).

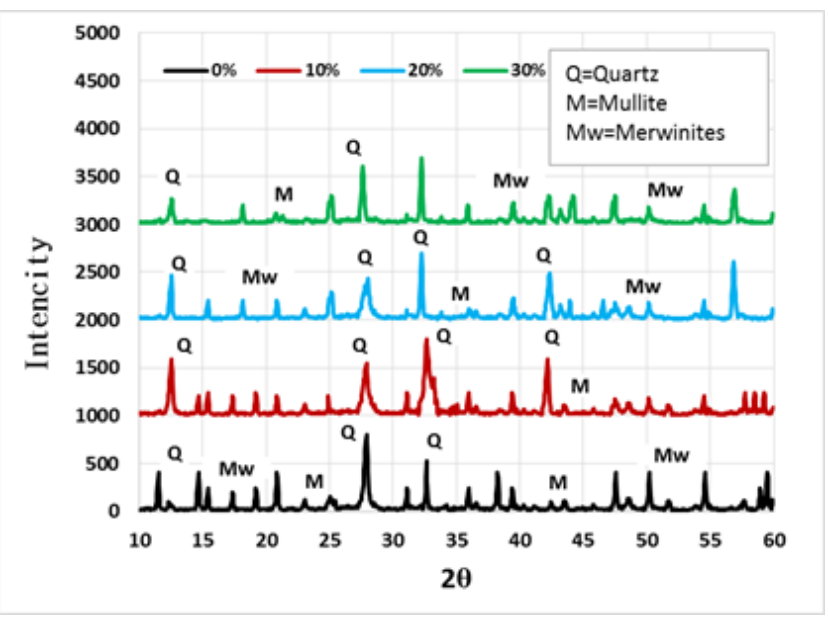

Figure 5. X-ray patterns for geopolymer concrete at $28 \mathrm{~d}$ and 2 $\mathrm{mm}$ maximum size of CTR

Scanning electronic photographs of different specimens prepared in this investigation were carried out in order to study the reactants of fly ash and to authenticate the internal microstructure of geopolymerization. The SEM photographs of control, M10, M20, and M30 with $2 \mathrm{~mm}$ chopped tire rubber, at 28d, are shown in Figure 6 (a to d). The aggregate matrix interface of the fracture surfaces for samples with chopped tire rubber do not possess any indication of cracking like that found in control specimen in Figure 5-a. It is also obvious from Figure 6-b that the addition of CTR enhanced the microstructure of geopolymer for M10 associated with thicker ITZ. This may be due to the more rough surface texture of the chopped tire rubber which leads to good interlocking with geopolymer matrix. In addition, increasing the CTR to 20 and $30 \%$ as shown in Figures 6 -c and 6-d initiate additional 
voids in the internal microstructure and this is definitely the main reason for density and compressive strength reduction at hardened state. Same observations were noticed by Embong et al. (2016) and Gandoman and Kokabi (2015).
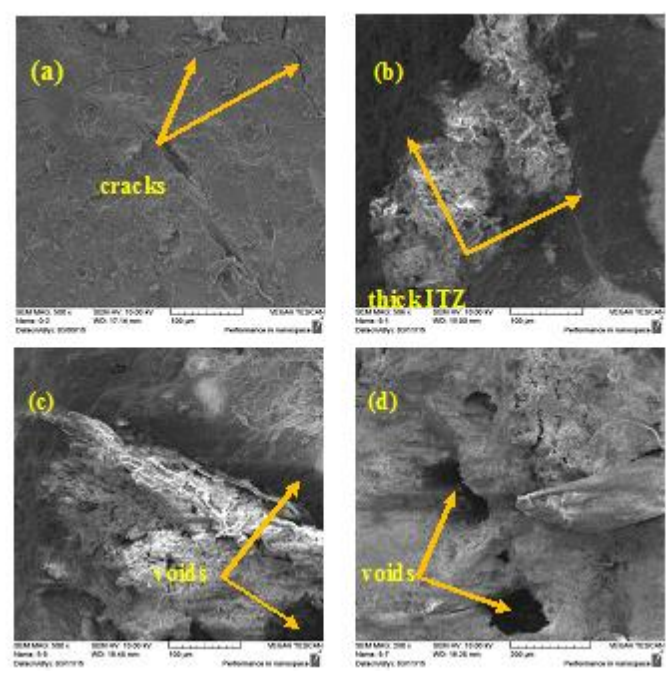

Figure 6. SEM photographs of geopolymer concrete at $28 \mathrm{~d}(\mathrm{a})$ control, (b) M10, (c) M20 and (d) M30 of 2 mm CTR

\section{Conclusions}

Based on the materials used and the results obtained, conclusions can be drawn:

1. Higher compressive strength was gained using chopped tire rubber as a replacement by volume of the fine aggregate of not more than $10 \%$. On contrast, higher fractions (20 and 30\%) of chopped tire rubber, lower compressive strength, density and UPV were observed.

2. Reducing the CTR maximum size from $4 \mathrm{~mm}$ to 2 $\mathrm{mm}$ resulted in an increase in the mechanical performance of fly ash based geopolymer concrete by $20 \%$. The geopolymer concrete made with CTR has a lower density than normal concrete by $19 \%$. Its bulk density ranged between $1873-2174 \mathrm{~kg} / \mathrm{m} 3$ when the CTR/sand range from $10-30 \%$.

3. The employment of CTR as a partial replacement by volume of sand was found to a maximum reduction in the ultrasonic pulse velocity of geopolymer concrete by 20.5 and 30.4 for 2 and 4 $\mathrm{mm}$ CTR respectively at 28 days.

4. It was found that Quartz was the highest reaction peaks and lower peaks correspond to the Aluminum Mullites, and Merwinites, are also noticed. Trace amounts of calcium silicates were also found in the final product.

5. The XRD examination shows highest peaks intensities were observed at $2 \theta=28.1^{\circ}$ for control mix due to the presence of Quartz. After the addition of CTR, highest peaks intensities were observed at $2 \theta=32.3^{\circ}$ for $\mathrm{M} 10, \mathrm{M} 20$ and $\mathrm{M} 30$ respectively.

6. SEM analysis revealed that the fracture surfaces for samples with CTR do not possess any cracking like that found in control. Further, increasing the CTR to $20 \%$ and $30 \%$ produces voids in the internal microstructure of geopolymer concrete.

\section{Acknowledgements}

The authors thank for Kerbala Technical Institute, Al-Furat AlAwsat Technical University for helping in the preliminary examination of raw materials.

\section{References}

Ali I.M., Naje A.S., Al-Zubaidi H.A.M. and Al-Kateeb R.T. (2019), Performance evaluation of fly ash-based geopolymer concrete incorporating nano slag, Global Nest Journal, 21(1), 70-75.

Al-Shathr B., Shamsa M. and al-Attar T. (2019), Relationship between amorphous silica in source materials and compressive strength of geopolymer concrete. MATEC Web of Conferences, vol. 162. EDP Sciences.

Al-Shathr B.S. and Al-Attar T.S. (2016), Effect of Curing System on Metakaolin Based Geopolymer Concrete, Journal of University of Babylon, 24(3), 569-576.

ASTM C311/C311M (1984), Standard Test Methods for Sampling and Testing Fly Ash or Natural Pozzolans for Use in PortlandCement Concrete. ASTM International, West Conshohocken, PA.

ASTM C494/C494M, ASTM 494/C 494M (1984), Standard Specification for Chemical Admixtures for Concrete. ASTM International, West Conshohocken, PA.

ASTM C618 (1984), Standard Specification for Coal Fly Ash and Raw or Calcined Natural Pozzolan for Use in Concrete. ASTM International, West Conshohocken, PA.

Bernal S.A., Rodríguez E.D., de Gutiérrez R.M., Gordillo M. and Provis J.L. (2011), Mechanical and thermal characterisation of geopolymers based on silicate-activated metakaolin/slag blends, Journal of Materials Science, 46(16), 5477-5486.

BS 1881: Part 114 (1983), Testing concrete: methods for determinations of density of harden concrete. British Standards Institution, UK.

BS 1881: Part 116 (1983), Method for determination of compressive strength of concrete cubes. British Standards Institution, UK.

BS 1881: Part 203 (1986), Recommendations for Measurement of Velocity of Ultrasonic Pulses in Concrete. British Standards Institution, UK.

Davidovits J. Geopolymer Chemistry and Applications. 4th edition, Institute Geopolymer, France.

Embong R., Kusbiantoro A., Shafiq N. and Nuruddin M.F. (2016), Strength and microstructural properties of fly ash based geopolymer concrete containing high-calcium and waterabsorptive aggregate, Journal of Cleaner Production, 112, 816-822.

Gandoman M. and Kokabi M. (2015), Sound barrier properties of sustainable waste rubber/geopolymer concretes, Iranian Polymer Journal (English Edition), 24(2), 105-112, https:// doi.org/10.1007/s13726-014-0304-1. 
Iraqi Standard No. 45 (1984), Aggregate from Natural Sources for Concrete and Building Construction. Central Organization for Standardization and Quality Control, Baghdad, Iraq.

Kim J.S. and Kim T.H. An Ultrasonic Pulse Velocity Test on Fly-Ash Based Geopolymer Concrete in Frequency Domains. Applied Mechanics and Materials, vol. 700. Trans Tech Publ p. 310313.

Komljenović M., Baščarević Z. and Bradić V. (2010), Mechanical and microstructural properties of alkali-activated fly ash geopolymers, Journal of Hazardous Materials, 181(1-3), 3542.

Kumaravel S. and Sivakumar I. (2018), Influence of Fiber Reinforced Geopolymer Concrete, International Journal of Research and Analytical Reviews, 5(4), 111-114.

Kurtoglu A.E., Alzeebaree R., Aljumaili O., Nis A., Gulsan M.E., Humur G., et al. (2018), Mechanical and durability properties of fly ash and slag based geopolymer concrete, Advances in Concrete Construction, 6(4), 345.

Maranan G.B., Manalo A.C., Benmokrane B., Karunasena W. and Mendis P. (2015), Evaluation of the flexural strength and serviceability of geopolymer concrete beams reinforced with glass-fibre-reinforced polymer (GFRP) bars, Engineering Structures, 101, 529-541, 2015.

Mulholland M. and Hibbert D.B. (1997), Linearity and the limitations of least squares calibration, Journal of Chromatography A, 762(1-2), 73-82, 1997, https://doi.org/ 10.1016/S0021-9673(96)00976-4.

Nurruddin M.F., Haruna S., Mohammed B.S. and Sha'aban I.G. (2018), Methods of curing geopolymer concrete: A review, International Journal of Advanced and Applied Sciences, 5(1), 31-36.

Parveen., Singhal D., Junaid M.T., Jindal B.B. and Mehta, A. (2018), Mechanical and microstructural properties of fly ash based geopolymer concrete incorporating alccofine at ambient curing, Construction and Building Materials, 180, 298-307.

Shanthini D., Grija S., Abinaya S. and Devaki R. (2016), Fibre Reinforced Geopolymer Concrete-A Review, International Journal of Civil Engineering and Technology, 7(5), 435-438. 